Hierauf baute er seinen 1956 erschienenen Artikel Zur ethnischen Geschichte der ostseefinnischen Stämme. Auch zahlreiche andere Aufsätze von ihm zeugen für ein besonderes Interesse an der Nationalitätenfrage: vor allem beschäftigten ihn der Ursprung der baltischen und finnisch-ugrischen Völker und deren Siedlungsgebiete in vorgeschichtlicher Zeit.

Harri Moora war auf seinem Forschungsgebiet unermüdlich tätig. Seine selbständige Betrachtungsweise, seine Gründlichkeit und seine reichen Kenntnisse verschafften ihm die Stellung eines anerkannten und geschätzten Forschers. Bescheidenheit, Aufopferung und Gerechtigkeit waren die Grundzüge seiner Persönlichkeit.

Ella Kivikoski

\title{
A. O. Väisänen
}

\section{$1890-1969$}

Am 18. Juli 1969 verstarb A. O. Väisänen, Prof. emer. für Musikwissenschaften an der Universität Helsinki.

Professor A. O. Väisänen sammelte, veröffentlichte und erforschte Volksmusik, erklärte Fragen der musikalischen Tonund Rhythmuslehre sowie der Thematik, er sammelte und beschäftigte sich intensiv mit der Volksdichtung, er organisierte den Musikunterricht und nahm führend daran teil und war im kulturellen Leben vielseitig tätig.

Armas Otto Aapo (Abraham) Väisänen wurde als Sohn eines Kaufmannes am 9. April 1890 in Savonranta geboren. Am Reallyzeum von Savonlinna legte er 1909 das Abitur ab, wurde 1919 Magister und 1939 Dr.phil. an der Universität Helsinki. Dieselbe Universität ernannte ihn 1940 zum Dozenten für Volksmusikforschung und $1956 \mathrm{zum}$ Professor für Musikwissenschaften.

Das Wesentlichste seiner veilseitigen Lebensarbeit gehört in den Bereich der Überlieferungsforschung; damit beschäftigte er sich in seiner Heimat bereits als Schüler. Väisänen unternahm insgesamt achtzehn wissenschaftliche Forschungsreisen ins Terrain: 1912-1923 sechs Fahrten nach Estland, i.J. 1914 begab er sich nach Westingermanland und zu den Mordwinen im Kreis Samara, 1915 und 1918 besuchte er Weissmeerkarelien, 1916 die südlichen Wepsen und 1919 Olonetz-Karelien. I. J. 1926 zeichnete er bei den Skoltlappen von Petsamo Volksüberlieferung auf und j.J. 1946 bei den Lappen in Schweden. Im finnischen Karelien sammelte er in d.J. 1916, 1917, 1919, 1920 und 1927. Die Ausbeute an Melodien umfasst ca. 6000 Auf- 
zeichnungen, der überwiegende Teil unter Verwendung des Phonographen und Parlographen. Das handgeschriebene Textmaterial enthält alte Lieder, Klagelieder, joiku-Gesänge und Erklärungen. Ein Teil der auf Wachszylinder aufgenommenen Proben wurde später auf Tonband übertragen. Eine Anzahl von Phonogrammen aus Estland wurde im Zusammenhang mit den Ereignissen des Jahres 1918 zerstört.

Der Umfang und die Vielseitigkeit des Materials zeugen von einer Feldarbeit sehr breiten Spektrums. Zu Fuss, im Boot, reitender-, oder fahrenderweise zog Väisänen als Student von einem Dorf zum anderen und vervollständigte seine Sammlungen gesungener und gesprochener Überlieferungen durch Fotografien aus dem Volksleben sowie durch Instrumente und Volkstrachten. Diese Sachgegenstände und Aufnahmen befinden sich im Finnischen Nationalmuseum in Helsinki, im Museum von Häme, im Institut für Volkskunde an der Universität Tampere, im Estnischen Nationalmuseum, im Nordiska Museet in Stockholm und im Museum für Musikinstrumente in Berlin.

Die wichtigsten Melodienpublikationen, die auf Väisänens eigenen Sammelergebnissen aufbauen, sind "Kantele- ja jouhikkosävelmiä" (Kantelemelodien) 1928 und "Mordwinische Melodien" 1948. Er redigierte und schrieb die Noten für den Band "Wogulische und ostjakische Melodien" 1937, welches Material Artturi Kannisto und K. F. Karjalainen auf Phonographenzylinder aufgenommen hatten. In seinem Nachlass befinden sich ferner an tausend fertig mit Noten versehene, ungedruckte Melodienproben: Signale, Hirtenmelodien, Klagelieder, Kinderlieder und andere Volksmelodien.

Mit der Herausgabe der genannten Materialveröffentlichungen ist natürlich auch wissenschaftliche Arbeit verbunden; an eigentlichen Abhandlungen aber verdanken wir Väisänen drei verschiedene Arbeiten sowie mehrere kleinere Untersuchungen. Das Hauptwerk bildet seine Dissertation »Untersuchungen über die obugrischen Melodien" 1939. Die Phasen und Ergebnisse des Sammelns finnischer Volksmusik werden behandelt in der Arbeit "Suomen kansan sävelmäin keräys" 1917. Am Anfang Ger Arbeit "Kantele- ja jouhikkosävelmiä" steht ein Kapitel üLer die frühen Typen des finnischen Nationalinstruments, über die Konstruktion und die Spielarten der Kantele, das auch für die spätere Kanteleforschung richtungsweisend wurde. Auch der Verfasser selbst schätzte diese Arbeit besonders. In anderen Studien untersuchte er die Kantele ferner im Zusammenhang mit den europäischen Instrumenten. Professor Väjsänen hat die Kanteleforschung in Finnland eingeleitet. Er interessierte sich ausserdem für die übrigen finnischen und finnisch-ugrischen Instrumente, u.a. die finnische jouhikantele 
bzw. jouhikko (ein zitherartiges Instrument mit 2 od. 3 Rosshaarsaiten), die kannel der Wepsen und Esten, das Harfen- und Leierinstrument der Obugrier, ja sogar für die Gusli der Russen und die Instrumente im Alten Testament.

Die Darlegungen über die Klagelieder, enthalten in den ca. 150 Nummern umfassenden Artikeln, zeugen besonders von dem genauen Gehör für Musik und Sprache, das A.O. Väisänen eigen war. Sein Verdienst ist es auch, die weissmeerkarelischen joiku-Gesänge für die Wissenschaft bekanntgemacht zu haben (s. Aika 2/ 1917). Besonders wertvoll sind seine Ergebnisse zu den Gesangsmelodien in "Kalevalan sävelmä» 1949. Melodien und Metrum der alten finnischen Lieder waren ihm derart vertraut, dass er sich auch selbst in dieser Kunst versuchte, was ihm im engeren Kreise scherzhaft den Namen "Väisämöinen" eintrug. Bei Bedarf schmiedete er am Schreibtisch schnell ein Gedicht im Kalevala-Metrum oder er übersetzte ein betreffendes Lied. Aus estnischen Liedern stellte er 1924 die ins Finnische übertragene Sammlung "Heimokannel" zusammen und aus russischen 1946 "Muinais-Venäjän sankarirunoja».

Prof. Väisänen nahm aktiv und vielseitig am kulturellen Leben teil; ein Beweis dafür ist seine Tätigkeit als Archivverwalter, Sekretär, Vorsitzender und Ehrenmitglied der Kalevalaseura.

Armas Otto Väisänen, einer der späten Vertreter finnischer Nationalromantik, der in der Volkskultur einen lebendigen Quell fand, weilt nicht mehr unter uns. Ihm, der die volkstümlichen künstlerischen Überlieferungen erforschte und pflegte, sind wir zu Dank verbunden. 